\title{
Dance therapy for individuals with Parkinson's disease: improving quality of life
}

This article was published in the following Dove Press journal:

Journal of Parkinsonism and Restless Legs Syndrome

2I February 20I4

Number of times this article has been viewed

\section{Madeleine E Hackney ${ }^{1-3}$ Crystal G Bennett ${ }^{4,5}$}

'Veterans Affairs Rehabilitation R\&D Center of Excellence, Atlanta, GA, USA; ${ }^{2}$ Birmingham-Atlanta VA Geriatric Research, Education and Clinical Center, Decatur, GA, USA; ${ }^{3}$ Division of General Medicine and Geriatrics, Department of Medicine, Emory University School of Medicine, Atlanta, GA, USA; ${ }^{4}$ Department of Nursing, University of West Florida, Pensacola, FL, USA; ${ }^{5}$ Department of Adult and Elderly Nursing, College of Nursing, University of Florida, Gainesville, FL, USA
Correspondence: Madeleine E Hackney PhD Research Health Scientist, Atlanta VA Medical Center, 1670 Clairmont Rd, Decatur, GA 30033, USA

Tel +I 404 32I 6I II, ext 5006

Cell + I 3I4 4I2 4852

Email mehackn@emory.edu; madeleine. hackney@gmail.com

\begin{abstract}
Parkinson's disease (PD) affects mobility and health-related quality of life (HRQOL), through a neurodegenerative disease process. Drugs and pharmacology do not fully address motor, cognitive, and psychosocial symptoms; therefore, adjunctive therapies have been researched for their efficacy at addressing these issues. One form of exercise, dance, has received attention because recent studies have demonstrated dance's ability to improve mobility and HRQOL in people with PD. The purpose of this integrative review was to present evidence supporting or refuting improved HRQOL in individuals with PD after participation in a danceor music-based movement intervention. Potential mechanisms of HRQOL improvement are offered. Search terms including "Parkinson's disease", "dance”, "quality of life", "exercise", "dance/movement therapy", and "music" were entered in groupings into PubMed, CINAHL ${ }^{\circledR}$, EMBASETM $^{\mathrm{TM}}$ PsycINFO ${ }^{\circledR}$, Web of Science ${ }^{\mathrm{TM}}$, and the Cochrane Library databases. Papers were included if they were randomized controlled trials, pilot studies, or case reports that were related to HRQOL and dance/movement and/or specifically related to determining the mechanisms potentially underlying dance effects. To date, the available research has been inconclusive in demonstrating that dance has a positive impact on HRQOL; however, further research is required. This review suggests that, at the very least, dance has the potential to impact the HRQOL and possibly the health behaviors of individuals with PD. Interventions for those with PD must be targeted and efficient. Going forward, research should explore mechanisms of dance's effects for those with neurodegenerative conditions in order to inform novel mobility rehabilitation that benefits HRQOL.
\end{abstract}

Keywords: exercise, music, QOL, mobility rehabilitation, intervention, neurodegenerative

\section{Introduction}

Parkinson's disease (PD) is a common neurodegenerative disorder affecting close to one million adults in the United States. By 2030, the number of people living with PD is expected to double because of the increasing aging population. ${ }^{1}$ Due to the progressive worsening of PD-related symptoms, management and treatment of this disease can be costly. Common symptoms of PD include tremor, bradykinesia, postural instability, and gait impairments, which often lead to lost independence. PD can also severely impact psychological and cognitive aspects of well-being. ${ }^{2}$ Non-motor manifestations of PD, specifically declining emotional health and health-related quality of life (HRQOL), may in fact precede the diagnosis of PD by several years. ${ }^{3}$

HRQOL is "the perception and evaluation by patients of the impact that the illness and its consequences have caused in their life". ${ }^{4}$ Self-assessed health status has been demonstrated to be more powerful at predicting mortality and morbidity than many 
objective measures of health. ${ }^{5,6}$ HRQOL measures, which are generally self-reported and related to physical or mental health, make it possible to demonstrate scientifically the impact of health on quality of life (Center for Disease Control, http:// www.cdc.gov/hrqol/concept.htm). Several valid, reliable and standardized measures have been used to assess HRQOL and related concepts, eg, the Medical Outcomes Study Short Forms 12 and 36 7,8 (SF-12 and SF-36). The Parkinson's Disease Questionnaire (PDQ)-39 $9^{9}$ is a PD-specific measure of HRQOL and is used widely. The self-reported information gathered concerning HRQOL in individuals with PD is gaining importance as an outcome measure for long-term trials. $^{10}$

HRQOL is affected early in PD by multiple non-motor symptoms. ${ }^{11}$ As the disease progresses, a collage of motor, affective, and behavioral symptoms often leads to considerably reduced HRQOL for many with PD. ${ }^{12}$ Mood disorders, impaired cognition, and sleep patterns worsen, which contribute to increased stress and social isolation over time..$^{13,14}$ HRQOL is particularly affected by depression, which is comorbid with PD in nearly half of those affected by the disease. Although PD is classically thought to be a "movement disorder", motor symptom treatment cannot be the sole concern in care. HRQOL in PD must be addressed with appropriate therapies.

\section{Does increased social engagement and better motor function improve HRQOL in individuals with PD?}

Addressing issues of well-being for those with PD is important because psychological adjustment to the effects of PD can have greater impact on HRQOL than disease severity. ${ }^{13}$ Increased depression, anxiety, and stress levels are significantly associated with increased problems in self-reported social support. ${ }^{15} \mathrm{Life}$ goal disturbance as a result of neurological disease may impact HRQOL, mood, and independence. ${ }^{14}$ Relationship goals with partner and family are often of utmost importance to those with PD. ${ }^{14}$ Axial impairment adversely impacts HRQOL in those with $\mathrm{PD}^{16,17}$ as well. Therefore, therapeutic interventions that foster achievable life goals and improve social network size and quality, while concurrently targeting motor impairments, are necessary for enhancing mood function and HRQOL of individuals with PD. ${ }^{14}$

Exercise therapy may reduce axial impairment, alleviate depression, and by proxy, enhance HRQOL. ${ }^{18}$ Higher levels of physical activity are associated with significantly less apathy and depression, while promoting greater positive affect in individuals with PD. ${ }^{19}$ Recently, a series of studies has examined a form of exercise, dance, for its effects on mobility, and postural control in people with PD. An adapted form of Argentine tango, ${ }^{20,21}$ Irish set dancing, ${ }^{22}$ contact improvisation, ${ }^{23}$ and modern dance, ${ }^{24}$ among other forms of dance, have been demonstrated to have beneficially affected mobility in those with PD. Because social dance often involves meeting regularly to work in pairs or groups for honing skill and/or to enjoy the activity, dance may encourage teamwork, which can allow the cultivation of friendships and may foster larger community involvement and social support. Dancing also necessitates the practice of dynamic balance and adjustment to environment, which are key features for rehabilitating balance impairments. ${ }^{25}$ Many individuals find dance enjoyable and engaging, which could promote adherence and enhance motivation for rehabilitative purposes. ${ }^{26,27}$ Because of these qualities, when used as an intervention for individuals with motor impairments, dance may contribute to improved HRQOL for individuals with PD. ${ }^{28,29}$

Dance's effects upon HRQOL have been studied in other populations. A randomized controlled trial (RCT) of 162 adult participants who suffered from stress, demonstrated that dance/movement therapy was effective at improving short- and long-term HRQOL, as measured by the World Health Organization QOL questionnaire, compared with usual care. ${ }^{30} \mathrm{~A}$ similar large-scale trial examining dance's effects on HRQOL in PD is not currently available; however, a handful of smaller trials have explicitly examined this construct.

Two former reviews have examined the effects of dance for people with PD. An early review by Earhart included studies from 1989 to 2009, only one of which had examined HRQOL ${ }^{31}$ Evidence, compiled in a rigorous meta-analysis by de Dreu et $\mathrm{al}^{32}$ on music-based movement therapies for those with PD, suggested only a trend towards improved HRQOL, as measured by a happiness scale. However, de Dreu et al ${ }^{32}$ ultimately included only six studies in their rigorous systematic meta-analysis. The present review, in contrast, provides a broader perspective about the state of research into HRQOL and dance, ie, rhythmic multimodal movement and movement set to music, for PD and will present several mechanisms by which dance might beneficially influence HRQOL.

\section{Purpose and methods of this integrative review}

The main aim of this review was to critically evaluate the evidence for the use of dance and movement therapies that employ music to improve HRQOL for individuals with PD 
as well as for other populations at risk for loss of physical function and decreased HRQOL. This was accomplished in the integrative format by synthesizing the findings of selected studies. This review also postulates mechanisms by which dance could impact HRQOL in individuals with PD. The following methods were used for this integrative review. Search terms were entered into databases, and entries were reviewed for appropriateness and inclusion in the paper. Systematic reviews, meta-analyses, RCTs, case studies, and smaller pilot trials that included individuals with PD or other neurological disorders, other comorbidities (ie, breast cancer), or older adults and were related to improved HRQOL or to determining the mechanisms of dance effects upon HRQOL were included. Perspective pieces, purely qualitative reviews, and trials involving non-dance- or music-related interventions were excluded. Papers about non-PD populations were included because relatively little research has been specifically conducted on dance's effects on HRQOL. Conference proceedings were not included, nor were non-English language papers. Both authors and a research assistant began with a PubMed search using the following groups of terms consecutively: "Parkinson's", "dance", and "quality of life" (13 entries), then "Parkinson's", "exercise", and "quality of life" (125 entries), "Parkinson's" and "dance" (45 entries), and "Parkinson's "music", "quality of life" and "health related quality of life" (10 entries). The journals American Journal of Dance Therapy and Music and Medicine were also reviewed for appropriate titles and abstracts. Next, the first author and a research assistant reviewed the following databases: PsycINFO $^{\circledR}$ (23 entries), Web of Science ${ }^{\mathrm{TM}}$ (5 entries), CINAHL $^{\circledR}$ ( 6 entries), Cochrane Library databases ( 3 entries), and EMBASETM (97 entries), for a total of 152 additional entries. Eighty-four of these were inappropriate upon review. Fifty-four entries were redundant with the previous PubMed search, leaving 14 additional papers that were, at the onset, appropriate for inclusion. Three of these were not obtainable, and of the remaining eleven papers, six were deemed inappropriate upon review. Five more papers were included from the secondary search.

\section{Do dance and exercise affect HRQOL? \\ What are dance and exercise's effects in community-dwelling older adults?}

Understanding how dance affects HRQOL in communitydwelling older adults will provide perspective in comprehending dance's effects, if any, upon HRQOL in those with PD. Research on dance's effects has been conducted upon not only motor, but also cognitive and psychosocial function of the healthy older adult population. In an RCT with healthy older participants, improvements in general and mental health aspects of HRQOL were found following 8 weeks of folklore dance, while the control group experienced declines. ${ }^{33}$ Another study which included 111 older adults who participated in 23 sessions of dance over 12 weeks improved in mobility and general health (measured by the SF-36) and believed their health status was improved by the intervention. ${ }^{34}$ In a study of Korean dance for older adults, ${ }^{35}$ improvements were found in social interaction components of HRQOL. Likewise, in a qualitative study conducted in Brazil, 60 participants in a ballroom dancing intervention that met for 1 hour, twice weekly for 1 year, reported dancing gave them opportunity to socialize and increase their connection to their own culture. ${ }^{36}$ In a pilot study examining adapted tango for oldest-old adults with low vision, along with improvements in postural stability, there was a significant positive change on vision-related quality of life in 12 participants. ${ }^{37}$

\section{What are dance's effects upon HRQOL in individuals with PD?}

Dance research conducted in older adults has led to the examination of dance's effects for individuals with PD. Studies examining the effects of dance forms in varying regimens on HRQOL in those with PD have revealed: 1) dance can be safe and enjoyable and can improve HRQOL; ;1,38,39 2) dance may have an early effect on HRQOL, as improvements have been found after as few as 2 weeks; ${ }^{23}$ and 3) dance may improve HRQOL in those with a severe and/or end-stage neurological disorder. ${ }^{40,41}$ However, RCTs examining HRQOL with PD participants assigned to a dance intervention have been very limited. Thirteen studies are examined here that involved a movement intervention for people with PD. There were seven RCTs, five single-arm (no-control) trials, and one case report (Table 1).

Volpe et $\mathrm{al}^{22}$ did not determine any significant difference in effects upon HRQOL between Irish dancing and physiotherapy, although both groups experienced non-significant improvements on the PDQ-39. In contrast, a study investigating effects of tango dance found improvements in activity participation following 12 months of the intervention. ${ }^{39}$ Additionally, in an RCT of 32 participants with PD, music therapy involving strongly rhythmic body movement demonstrably improved scores on the PD Quality of Life questionnaire..$^{42}$ In 12 participants with $\mathrm{PD}$ who engaged in the Ronnie Gardiner Rhythm and Music Method twice 


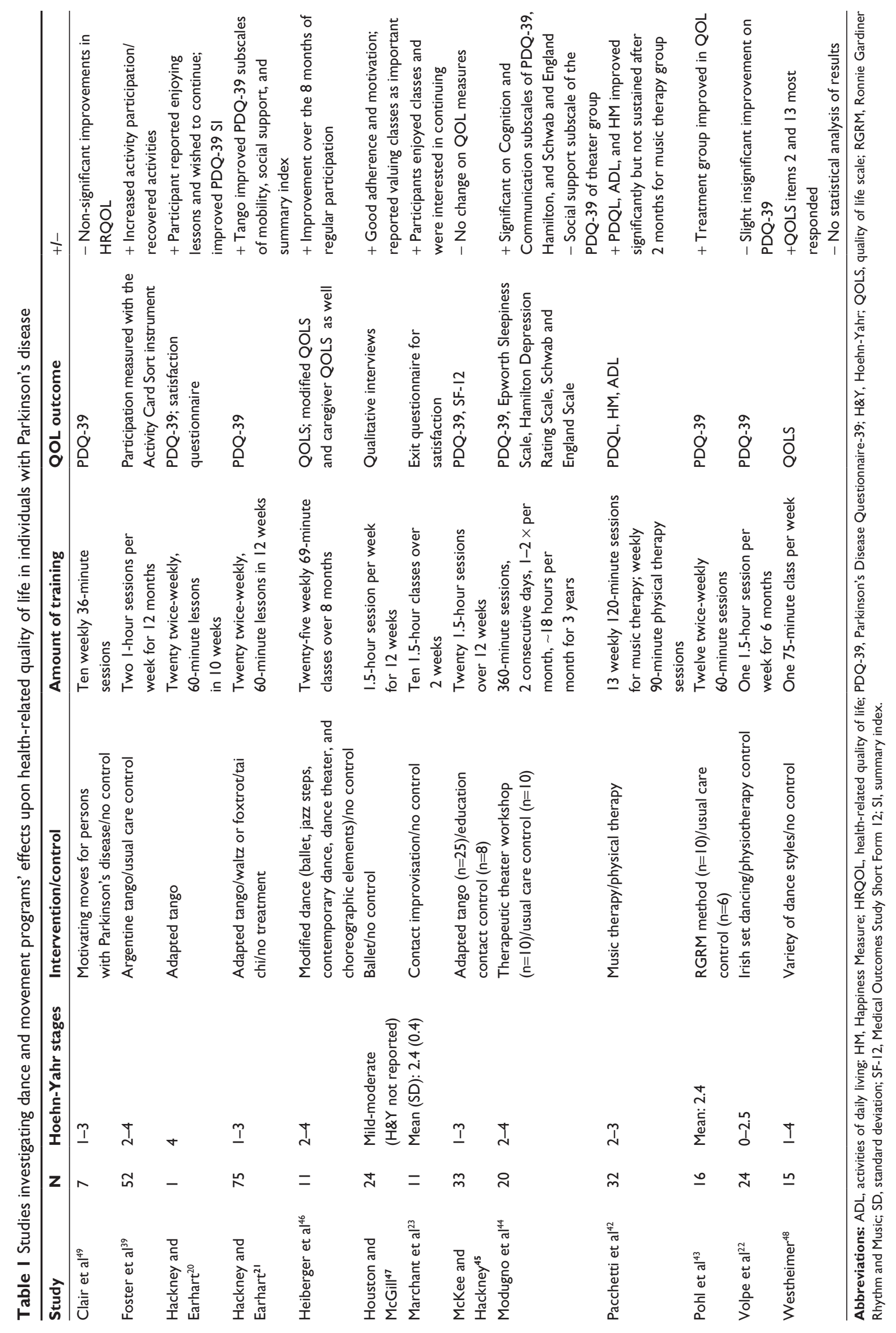


weekly over 6 weeks, improved HRQOL scores were noted. ${ }^{43}$ A theatrical movement therapy examined in 20 patients with PD over 3 years resulted in improved HRQOL ${ }^{44}$ as measured by the standard, valid, and reliable PDQ-39, which measures subjective health status. A recent study that primarily examined the effects of adapted tango on spatial cognition in individuals with PD also explicitly examined HRQOL with the PDQ- $39^{9}$ and the SF-12, ${ }^{7}$ which have satisfactory clinimetrics. However, no changes were noted on either scale, in comparison with an education control group. ${ }^{45}$

In studies of individuals with PD without a control group, improvements in HRQOL were noted in eleven individuals with PD after participation in contemporary dance. ${ }^{46}$ Also, those with PD who participated in contact improvisation $(n=11)$ self-reported enjoyment and interest in dance classes. ${ }^{23}$ Furthermore, improvements in HRQOL were found in a case study of a severely mobility-impaired participant with Stage V PD. ${ }^{40}$ In a mixed-methods study examining the effects of a ballet class that included participants with $\mathrm{PD},{ }^{47}$ the participants reported being highly motivated and valued dance as being important. When evaluated, modern dance in the guise of the very popular "Dance for PD" class format showed a trend towards positive influence on HRQOL in those with PD in an uncontrolled study. ${ }^{48} \mathrm{~A}$ movement class with strong musical cueing was beneficial for trunk rotation in seven individuals with PD, and there was a trend toward positive changes on several dimensions of the PDQ-39. ${ }^{49}$

That several of the studies investigating dance and free movement in PD have not been controlled and may have been subject to bias decreases the rigor of the body of work. Plus, many of the sample sizes were small. The results of these studies are therefore compromised because of study limitations, which weaken any evidence that supports improved HRQOL. More research that observes rigorous scientific methods needs to be performed to make conclusive inferences about dance's effects upon HRQOL in individuals with PD.

\section{What are dance's effects on other populations at risk for loss of function?}

Recent research has shown that other populations may have benefitted from participation in dance interventions of various types, through improved HRQOL. Improvements were found with an impaired individual with chronic stroke ${ }^{41}$ who selfreported that dance improved his HRQOL and that he enjoyed the dance classes. Improvements in HRQOL were found in a 13-week RCT of dance/movement therapy with participants with breast cancer. ${ }^{50}$ In a pilot study with individuals with serious mental illness who participated in salsa dance, participants reported improved mood, enjoyment of classes, and the desire to continue to dance. ${ }^{20}$ Further, compared with meditation and usual care, individuals with self-reported depression who participated in tango reported reduced stress. ${ }^{51}$ However, in a group of individuals with Huntington's disease who participated in the video game Dance Dance Revolution, gait improved, and participants were motivated to continue, but there were no significant improvements on measures of HRQOL. ${ }^{52}$ Further, a systematic review showed that dance/movement therapy was not found to be effective at improving self-constructs in breast cancer survivors. ${ }^{53}$ Thus, it is interesting and hopeful that some evidence indicates the efficacy of dance in improving HRQOL amongst multiple populations. However, the evidence is weak overall, because few studies have directly examined this construct in conjunction with dance- or music-based interventions, and there is a dearth of properly conducted RCTs. ${ }^{54}$

\section{What are the mechanisms through which dance may improve HRQOL?}

A number of mechanisms, including increased participation through enhanced motor function, mental imagery and engagement, music, and physiology, may mediate dance's effects upon HRQOL in those with PD, as well as other comorbid conditions.

\section{Does enhanced motor function lead to increased participation?}

A suggested hypothesis for why partnered dance would improve HRQOL is that in addition to improving balance impairment, dance involvement may reduce social isolation for those with PD. The World Health Organization's International Classification of Functioning, Disability and Health (ICF) takes into account social aspects of disability. In the ICF model, an individual's functioning in activities is an interaction between health condition, environmental, and personal contextual factors. People with PD experience physical and cognitive performance problems because of environmental factors interacting with their health condition and impairment. Loss of mobility leads to reduced ability to interact with a complex world. Physical and cognitive changes faced by those with PD may also preclude interacting in the hectic life environment that is reality for many. Participation, defined as involvement in a life situation, is especially related to mobility-related HRQOL and the ability to do functional tasks like rising from a chair. ${ }^{55}$ Potentially, some individuals 
with PD have benefitted in HRQOL through dance by the removal of barriers to participation (eg, availability of dance programs and motor challenges of the steps). Participation in a yearlong program of tango led to participants recovering lost activities, beginning new ones, and gaining the ability to engage in more complex activities. ${ }^{39}$

Exercise programs for individuals with PD that are selfguided may not be as helpful for HRQOL as programs that involve a supportive therapist or instructor. ${ }^{56}$ In a culturally specific dance study in which middle-aged and older AfricanAmerican women (ages 35-82 years) participated, social support was found to mediate the effects of the dance on lifestyle physical activity. ${ }^{57}$ Social support is undoubtedly important for improving HRQOL; however, the delivery of this support is relevant. A cohort with PD and their caregivers who did not participate in exercise but did receive educational information designed to increase social support and relieve stress and caregiver burden did not significantly improve on the PDQ-39, nor on the EuroQOL 5D, a questionnaire for caregivers. ${ }^{58}$ Therefore, the motor symptom improvement that can be gained from physical interventions like dance is especially important for enhancing HRQOL. Gait and balance are increasingly recognized as especially important for determinants of HRQOL as well as mortality. ${ }^{59}$ Dance may improve the axial impairment ${ }^{38}$ that greatly affects participation and also HRQOL in those with PD. ${ }^{60}$

\section{Mental imagery and engagement in motor practice}

Mental activity performed in a task-specific manner, as in dance, may be an important factor contributing to overall improved well-being. Mental practice and motor imagery can impact gait and tasks that require coordinated movements of lower extremities in those with PD and other populations. ${ }^{61}$ A mindful movement program aimed at improving HRQOL and mindfulness in older breast cancer survivors was moderately effective, and the effects were retained 6 weeks after the intervention. ${ }^{62}$ Healthy middle-aged adults who underwent tango training for 1 week and incorporated mental imagery of gait patterns demonstrated expanded bilateral motor activation. ${ }^{63}$ This finding shows that there is a strong link between activity, mental engagement, and neural pathways. Dancing, whether it be tango, contemporary, or folk dance, involves complex, unfamiliar tasks like walking backward, problem solving, and movement improvisation, which possibly target mobility issues in individuals with PD through increased mental engagement and strategy development. The creativity involved in a dance form might tap into mechanisms of neural plasticity for novices just beginning classes for therapy. The exposure to novel steps and choreographic patterns could, through the mechanisms of neural plasticity, expand neural areas and improve connections on neural pathways that facilitate HRQOL.

\section{Music}

Music, which has been found to activate specific neural pathways associated with emotion, might reduce stress and enhance social relationships. ${ }^{29}$ Music-therapy programs that include any consistent rhythmic auditory stimulation to facilitate motor movements are recommended for those with PD as a way to improve HRQOL. ${ }^{49}$ However, gross motor action coordinated to music may be essential for improving HRQOL, because choral singing alone did not result in improved HRQOL in 15 individuals with PD. ${ }^{64}$ The role that music may play in any significant improvements noted in HRQOL and possibly obtained through dance is not yet understood. More research is certainly needed to better characterize music's impact on dance used as therapy.

\section{Physiology and psychopathology}

Psychopathology in some individuals with PD, which often leads to reduced HRQOL, results from the underlying physiology of the disease. ${ }^{65}$ Neurotransmitter systems that are typically degraded in PD (eg, dopamine and serotonin) also contribute to depression. ${ }^{66}$ Decreased availability of the dopamine transporter in the anterior putamen correlates with depressive symptoms and anxiety. ${ }^{67}$ However, in a positron emission tomography study, rhythmic tango steps have been shown to selectively activate the putamen, ${ }^{68}$ an area of the brain particularly affected by the loss of dopamine in PD. Perhaps through this pathway, dance affects depressive symptoms. In an RCT of tango over 2 weeks (meeting 1.5 hours four times per week) with middle-aged adults with self-referred symptoms of anxiety, stress, and depression, significant improvements in anxiety, stress, and depression were noted at post-test, which were maintained at a 1-month follow-up. ${ }^{69}$ Moreover, those in the tango group had significantly greater satisfaction with life at 2 weeks. Likewise, similar improvements in stress, anxiety, and depression were noted in the same population after 8 weeks of tango dance. ${ }^{70}$

The neuroprotection and neurorestoration that may be derived from consistent, task-specific, and frequent aerobic exercise, which could be provided by dance, may extend into improved mood and capability to accomplish activities of daily living and thereby impact HRQOL. Individuals with 
severe and persistent mental illness notably benefitted in mood from salsa dancing, which is highly aerobic. ${ }^{71}$

After 36 sessions of aerobic and strength conditioning, individuals with PD demonstrated improvements in social interactions, emotional reactions, and physical ability on the Nottingham Health Profile, ${ }^{72}$ which is a patient-reported, subjective outcome measure of health and life areas affected by illness. ${ }^{73}$ Improvement gained potentially through plasticity-related changes in synaptogenesis, angiogenesis, and neurogenesis may have allowed older adults to benefit after regular aerobic activity. ${ }^{74}$

\section{Conclusion and recommendations for future research}

The definitive beneficial ingredients of dance for improved HRQOL require elucidation, but dance programs may have multidimensional effects on self-assessment. The departure from the daily routine in everyday lives of patients with PD may alone provide an effect that appears in improved HRQOL measure scores. Possibly, therapies involving the arts and self-expression, both emotional and physical, are especially helpful for managing symptoms leading to reduced HRQOL. Therapies that 1) allow the patient to regain and exert control on their body and 2) involve extensive social interaction have been shown to be effective at improving quality of life. ${ }^{44}$ Future research should evaluate the role of a regained locus of control and consider depression and cognitive impairment as they relate to interventional success on HRQOL as a primary outcome of interest. Furthermore, future research should include retention measures and delineate ideal frequency, duration, and intensity of dance sessions to obtain and retain gains in HRQOL.

Dance, which may benefit HRQOL, may also prove economic because group classes are comparatively inexpensive to administer. ${ }^{75,76}$ However, engaging in exercise habitually remains overwhelmingly poor in the general older adult population. An epidemiologic study reported only one in eight older adults engage in strength or balance-challenging activities. ${ }^{77}$ Individuals with PD are less active than their agematched peers without PD. ${ }^{78}$ Rehabilitation to restore and/or improve HRQOL in people with PD must be efficient as well as effective, because adherence to an exercise regimen is critical. Thus, identifying aspects of dance, which are most responsible for benefits to HRQOL or mediating symptoms, ie, axial impairment, will be important for adherence to exercise. Understanding these crucial aspects will also help determine foundational principles of motor training and emotional therapy. Creating sustained behavioral change through targeted programs may be most effective at addressing HRQOL issues. ${ }^{79}$

This review has considered the available evidence that examines whether dance and music-based movement therapies impact HRQOL and potentially other characteristics, eg, health behaviors, of individuals with PD, as well as those with related comorbid and neurological conditions. These early studies may provide fodder for future, more rigorous research into the effects of dance for various populations facing aging-related diseases. For the frequently overlooked issue of improving HRQOL for those with PD, dance interventions may be ideal because: 1) dance targets axial impairment and gait deficits that are major contributors to reduced HRQOL; 2) dance is a social activity that could enhance strong supportive relationships between those with PD, their caregivers, and other loved ones; and 3) dance is enjoyable and motivating, possibly promoting long-term, consistent involvement. Going forward, uncovering mechanisms may be the most important area of discovery for the investigation of non-pharmacologic interventions that address HRQOL issues. The knowledge and principles gained could impact not only dance disciplines but also physical, occupational, and emotional therapy for older adults with PD and related neurological disorders. With improved and/or maintained independence via enhanced mobility and an expanded social network, the overall goal of improving HRQOL in those with $\mathrm{PD}$ can be reached.

\section{Acknowledgments}

We would like to acknowledge our helpful staff, in particular, Aaron Bozzorg, for assisting us in the preparation of this manuscript as well as our prior and present colleagues who provided inspiration.

\section{Disclosure}

The authors report no conflicts of interest in this work. The authors alone are responsible for the content and writing of the paper. Department of Veterans Affairs (VA) Career Development Awards (E7108M and N0870W) supported Dr ME Hackney.

\section{References}

1. Dorsey ER, Constantinescu R, Thompson JP, et al. Projected number of people with Parkinson disease in the most populous nations, 2005 through 2030. Neurology. 2007;68(5):384-386.

2. Schrag A, Jahanshahi M, Quinn N. How does Parkinson's disease affect quality of life? A comparison with quality of life in the general population. Mov Disord. 2000;15(6):1112-1118.

3. Palacios N, Gao X, Schwarzschild M, Ascherio A. Declining quality of life in Parkinson disease before and after diagnosis. $J$ Parkinsons Dis. 2012;2(2):153-160 
4. Martinez-Martin P, Deuschl G. Effect of medical and surgical interventions on health-related quality of life in Parkinson's disease. Mov Disord. 2007;22(6):757-765.

5. Dominick KL, Ahern FM, Gold CH, Heller DA. Relationship of healthrelated quality of life to health care utilization and mortality among older adults. Aging Clin Exp Res. 2002;14(6):499-508.

6. DeSalvo KB, Bloser N, Reynolds K, He J, Muntner P. Mortality prediction with a single general self-rated health question. A meta-analysis. J Gen Intern Med. 2006;21(3):267-275.

7. Ware J Jr, Kosinski M, Keller SD. A 12-item short-form health survey: construction of scales and preliminary tests of reliability and validity. Med Care. 1996;34(3):220-233.

8. Ware JE Jr, Sherbourne CD. The MOS 36-item short-form health survey (SF-36). I. Conceptual framework and item selection. Med Care. 1992;30(6):473-483.

9. Peto V, Jenkinson C, Fitzpatrick R, Greenhall R. The development and validation of a short measure of functioning and well being for individuals with Parkinson's disease. Qual Life Res. 1995;4(3):241-248.

10. Opara JA, Brola W, Leonardi M, Blaszczyk B. Quality of life in Parkinson's disease. J Med Life. 2012;5(4):375-381.

11. Tolosa E, Compta Y, Gaig C. The premotor phase of Parkinson's disease. Parkinsonism Relat Disord. 2007;13 Suppl:S2-S7.

12. Duncan GW, Khoo TK, Yarnall AJ, et al. Health-related quality of life in early Parkinson's disease: the impact of nonmotor symptoms. Mov Disord. Epub October 7, 2013.

13. Suzukamo Y, Ohbu S, Kondo T, Kohmoto J, Fukuhara S. Psychological adjustment has a greater effect on health-related quality of life than on severity of disease in Parkinson's disease. Mov Disord. 2006;21(6): 761-766.

14. McNamara P, Durso R, Harris E. Life goals of patients with Parkinson's disease: a pilot study on correlations with mood and cognitive functions. Clin Rehabil. 2006;20(9):818-826.

15. Simpson J, Haines K, Lekwuwa G, Wardle J, Crawford T. Social support and psychological outcome in people with Parkinson's disease: evidence for a specific pattern of associations. Br J Clin Psychol. 2006; 45(Pt 4):585-590.

16. Scalzo PL, Flores CR, Marques JR, Robini SC, Teixeira AL. Impact of changes in balance and walking capacity on the quality of life in patients with Parkinson's disease. Arq Neuropsiquiatr. 2012;70(2):119-124.

17. Muslimovic D, Post B, Speelman JD, Schmand B, de Haan RJ. Determinants of disability and quality of life in mild to moderate Parkinson disease. Neurology. 2008;70(23):2241-2247.

18. Goodwin VA, Richards SH, Taylor RS, Taylor AH, Campbell JL. The effectiveness of exercise interventions for people with Parkinson's disease: a systematic review and meta-analysis. Mov Disord. 2008;23(5):631-640.

19. Abrantes AM, Friedman JH, Brown RA, et al. Physical activity and neuropsychiatric symptoms of Parkinson disease. J Geriatr Psychiatry Neurol. 2012;25(3):138-145.

20. Hackney ME, Earhart GM. Effects of dance on gait and balance in Parkinson's disease: a comparison of partnered and nonpartnered dance movement. Neurorehabil Neural Repair. 2010;24(4):384-392.

21. Hackney ME, Earhart GM. Effects of dance on movement control in Parkinson's disease: a comparison of Argentine tango and American ballroom. J Rehabil Med. 2009;41(6):475-481.

22. Volpe D, Signorini M, Marchetto A, Lynch T, Morris ME. A comparison of Irish set dancing and exercises for people with Parkinson's disease: a Phase II feasibility study. BMC Geriatr. 2013;13:54.

23. Marchant D, Sylvester JL, Earhart GM. Effects of a short duration, high dose contact improvisation dance workshop on Parkinson disease: a pilot study. Complement Ther Med. 2010;18(5):184-190.

24. Batson G. Feasibility of an intensive trial of modern dance for adults with Parkinson disease. Complement Health Pract Rev. 2010;15(2): 65-83.

25. Hirsch MA, Toole T, Maitland CG, Rider RA. The effects of balance training and high-intensity resistance training on persons with idiopathic Parkinson's disease. Arch Phys Med Rehabil. 2003;84(8):1109-1117.
26. Federici A, Bellagamba S, Rocchi MB. Does dance-based training improve balance in adult and young old subjects? A pilot randomized controlled trial. Aging Clin Exp Res. 2005;17(5):385-389.

27. Palo-Bengtsson L, Winblad B, Ekman SL. Social dancing: a way to support intellectual, emotional and motor functions in persons with dementia. J Psychiatr Ment Health Nurs. 1998;5(6):545-554.

28. Nombela C, Hughes LE, Owen AM, Grahn JA. Into the groove: can rhythm influence Parkinson's disease? Neurosci Biobehav Rev. 2013;37(10 Pt 2):2564-2570.

29. Boso M, Politi P, Barale F, Enzo E. Neurophysiology and neurobiology of the musical experience. Funct Neurol. 2006;21(4):187-191.

30. Bräuninger I. The efficacy of dance movement therapy group on improvement of quality of life: a randomized controlled trial. Arts Psychother. 2012;39(2012):296-303.

31. Earhart GM. Dance as therapy for individuals with Parkinson disease. Eur J Phys Rehabil Med. 2009;45(2):231-238.

32. de Dreu MJ, van der Wilk AS, Poppe E, Kwakkel G, van Wegen EE. Rehabilitation, exercise therapy and music in patients with Parkinson's disease: a meta-analysis of the effects of music-based movement therapy on walking ability, balance and quality of life. Parkinsonism Relat Disord. 2012;18 Suppl 1:S114-S119.

33. Eyigor S, Karapolat H, Durmaz B, Ibisoglu U, Cakir S. A randomized controlled trial of Turkish folklore dance on the physical performance, balance, depression and quality of life in older women. Arch Gerontol Geriatr. 2009;48(1):84-88.

34. Hui E, Chui BT, Woo J. Effects of dance on physical and psychological well-being in older persons. Arch Gerontol Geriatr. 2009;49(1): e45-e50.

35. Song R, June KJ, Kim CG, Jeon MY. Comparisons of motivation, health behaviors, and functional status among elders in residential homes in Korea. Public Health Nurs. 2004;21(4):361-371.

36. Lima MMS, Vieira AP. Ballroom dance as therapy for the elderly in Brazil. Arch Gerontol Geriatr. 2007;29(2):129-142.

37. Hackney ME, Hall CD, Echt KV, Wolf SL. Dancing for balance: feasibility and efficacy in oldest-old adults with visual impairment. Nurs Res. 2013;62(2):138-143.

38. Hackney ME, Kantorovich S, Levin R, Earhart GM. Effects of tango on functional mobility in Parkinson's disease: a preliminary study. J Neurol Phys Ther. 2007;31(4):173-179.

39. Foster ER, Golden L, Duncan RP, Earhart GM. Community-based Argentine tango dance program is associated with increased activity participation among individuals with Parkinson's disease. Arch Phys Med Rehabil. 2013;94(2):240-249.

40. Hackney ME, Earhart GM. Effects of dance on balance and gait in severe Parkinson disease: a case study. Disabil Rehabil. 2010;32(8): 679-684.

41. Hackney ME, Hall CD, Echt KV, Wolf SL. Application of adapted tango as therapeutic intervention for patients with chronic stroke. J Geriatr Phys Ther. 2012;35(4):206-217.

42. Pacchetti C, Mancini F, Aglieri R, Fundaro C, Martignoni E, Nappi G. Active music therapy in Parkinson's disease: an integrative method for motor and emotional rehabilitation. Psychosom Med. 2000;62(3):386-393.

43. Pohl P, Dizdar N, Hallert E. The Ronnie Gardiner Rhythm and Music Method - a feasibility study in Parkinson's disease. Disabil Rehabil. 2013;35(26):2197-2204.

44. Modugno N, Iaconelli S, Fiorlli M, Lena F, Kusch I, Mirabella G. Active theater as a complementary therapy for Parkinson's disease rehabilitation: a pilot study. Scientific World Journal. 2010;10:2301-2313.

45. McKee KE, Hackney ME. The effects of adapted tango on spatial cognition and disease severity in Parkinson's disease. J Mot Behav. 2013;45(6):519-529.

46. Heiberger L, Maurer C, Amtage F, et al. Impact of a weekly dance class on the functional mobility and on the quality of life of individuals with Parkinson's disease. Front Aging Neurosci. 2011;3:14.

47. Houston S, McGill A. A mixed-methods study into ballet for people living with Parkinson's. Arts Health. 2013;5(2):103-119. 
48. Westheimer O. Why dance for Parkinson's disease. Top Geriatr Rehabil. 2008;24(2):127-140.

49. Clair AA, Lyons KE, Hamburg J. A feasibility study of the effects of music and movement on physical function, quality of life, depression, and anxiety in patients with Parkinson disease. Music Med. 2012;4(1): $49-55$.

50. Sandel SL, Judge JO, Landry N, Faria L, Ouellette R, Majczak M. Dance and movement program improves quality-of-life measures in breast cancer survivors. Cancer Nurs. 2005;28(4):301-309.

51. Pinniger R, Brown RF, Thorsteinsson EB, McKinley P. Argentine tango dance compared to mindfulness meditation and a waiting-list control: a randomised trial for treating depression. Complement Ther Med. 2012;20(6):377-384

52. Kloos AD, Fritz NE, Kostyk SK, Young GS, Kegelmeyer DA. Video game play (Dance Dance Revolution) as a potential exercise therapy in Huntington's disease: a controlled clinical trial. Clin Rehabil. 2013;27(11):972-982.

53. Bradt J, Goodill SW, Dileo C. Dance/movement therapy for improving psychological and physical outcomes in cancer patients. Cochrane Database Syst Rev. 2011;(10):CD007103.

54. Strassel JK, Cherkin DC, Steuten L, Sherman KJ, Vrijhoef HJ. A systematic review of the evidence for the effectiveness of dance therapy. Altern Ther Health Med. 2011;17(3):50-59.

55. Duncan RP, Earhart GM. Measuring participation in individuals with Parkinson disease: relationships with disease severity, quality of life, and mobility. Disabil Rehabil. 2011;33(15-16):1440-1446.

56. Dereli EE, Yaliman A. Comparison of the effects of a physiotherapist-supervised exercise programme and a self-supervised exercise programme on quality of life in patients with Parkinson's disease. Clin Rehabil. 2010;24(4):352-362.

57. Murrock CJ, Madigan E. Self-efficacy and social support as mediators between culturally specific dance and lifestyle physical activity. Res Theory Nurs Pract. 2008;22(3):192-204.

58. Simons G, Thompson SB, Smith Pasqualini MC; Members of the EduPark consortium. An innovative education programme for people with Parkinson's disease and their carers. Parkinsonism Relat Disord. 2006;12(8):478-485.

59. Maetzler W, Nieuwhof F, Hasmann SE, Bloem BR. Emerging therapies for gait disability and balance impairment: promises and pitfalls. Mov Disord. 2013;28(11):1576-1586.

60. Marras C, McDermott MP, Rochon PA, et al. Predictors of deterioration in health-related quality of life in Parkinson's disease: results from the DATATOP trial. Mov Disord. 2008;23(5):653-659; quiz 776.

61. Malouin F, Richards CL. Mental practice for relearning locomotor skills. Phys Ther. 2010;90(2):240-251.

62. Crane-Okada R, Kiger H, Sugerman F, et al. Mindful movement program for older breast cancer survivors: a pilot study. Cancer Nurs. 2012;35(4):E1-E13.

63. Sacco K, Cauda F, Cerliani L, Mate D, Duca S, Geminiani GC. Motor imagery of walking following training in locomotor attention. The effect of "the tango lesson." Neuroimage. 2006;32(3):1441-1449.
64. Shih LC, Piel J, Warren A, et al. Singing in groups for Parkinson's disease (SING-PD): a pilot study of group singing therapy for PD-related voice/ speech disorders. Parkinsonism Relat Disord. 2012;18(5): 548-552.

65. Zurowski M, McDonald WM, Fox S, Marsh L. Psychiatric comorbidities in dystonia: emerging concepts. Mov Disord. 2013;28(7):914-920.

66. Lagopoulos J, Malhi GS, Ivanovski B, Cahill CM, Morris JG. A matter of motion or an emotional matter? Management of depression in Parkinson's disease. Expert Rev Neurother. 2005;5(6):803-810.

67. Weintraub D, Newberg AB, Cary MS, et al. Striatal dopamine transporter imaging correlates with anxiety and depression symptoms in Parkinson's disease. J Nucl Med. 2005;46(2):227-232.

68. Brown S, Martinez MJ, Parsons LM. The neural basis of human dance. Cereb Cortex. 2006;16(8):1157-1167.

69. Pinniger R, Thorsteinsson EB, Brown RF, Mckinley P. Intensive tango dance program for people with self-referred affective symptoms. Music Med. 2013;5(1):15-22.

70. Pinniger R, Thorsteinsson EB, Brown R, McKinley P. Tango dance can reduce distress and insomnia in people with self-referred affective symptoms. Am J Dance Ther. 2013;35(1):60-77.

71. Hackney ME, Earhart GM. Social partnered dance for people with serious and persistent mental illness: a pilot study. J Nerv Ment Dis. 2010;198(1):76-78.

72. Hunt SM, McKenna SP, McEwen J, Backett EM, Williams J, Papp E. A quantitative approach to perceived health status: a validation study. J Epidemiol Community Health. 1980;34(4):281-286.

73. Rodrigues de Paula F, Teixeira-Salmela LF, Coelho de Morais Faria CD, Rocha de Brito P, Cardoso F. Impact of an exercise program on physical, emotional, and social aspects of quality of life of individuals with Parkinson's disease. Mov Disord. 2006;21(8):1073-1077.

74. Hirsch MA, Farley BG. Exercise and neuroplasticity in persons living with Parkinson's disease. Eur J Phys Rehabil Med. 2009;45(2): 215-229.

75. Liu H, FrankA. Tai chi as a balance improvement exercise for older adults: a systematic review. J Geriatr Phys Ther. 2010;33(3):103-109.

76. Frick KD, Kung JY, Parrish JM, Narrett MJ. Evaluating the costeffectiveness of fall prevention programs that reduce fall-related hip fractures in older adults. J Am Geriatr Soc. 2010;58(1):136-141.

77. Merom D, Pye V, Macniven R, et al. Prevalence and correlates of participation in fall prevention exercise/physical activity by older adults. Prev Med. 2012;55(6):613-617.

78. Toth MJ, Fishman PS, Poehlman ET. Free-living daily energy expenditure in patients with Parkinson's disease. Neurology. 1997;48(1):88-91.

79. Speelman AD, van de Warrenburg BP, van Nimwegen M, Petzinger GM, Munneke M, Bloem BR. How might physical activity benefit patients with Parkinson disease? Nat Rev Neurol. 2011;7(9):528-534.
Journal of Parkinsonism \& Restless Legs Syndrome

\section{Publish your work in this journal}

Journal of Parkinsonism and Restless Legs Syndrome is an online, open access, peer-reviewed journal. The journal publishes review articles, historical reviews, original research articles, case reports, letters to the editor, clinical teaching cases, neuroradiology highlights, neuropathology highlights, neuropsychiatry highlights, autobiographies, conference
Submit your manuscript here: http://www.dovepress.com/journal-of-parkinsonism--restless-legs-syndrome-journal submit your manuscript | www.dovepress.com

Dovepress proceedings, abstracts and book reviews. The manuscript management system is completely online and includes a very quick and fair peerreview system, which is all easy to use. Visit http://www.dovepress.com/ testimonials.php to read real quotes from published authors. 